\title{
G-CSF and hypoxic conditioning improve the proliferation, neural differentiation and migration of canine bone marrow mesenchymal stem cells
}

\author{
JING YU ${ }^{1 *}$, XING-LONG LIU ${ }^{1 *}$, QI-GUANG CHENG ${ }^{2}$, SHAN-SHAN LU ${ }^{1}$, \\ XIAO-QUAN XU ${ }^{1}$, QING-QUAN ZU ${ }^{1}$ and SHENG LIU ${ }^{1}$ \\ ${ }^{1}$ Department of Radiology, First Affiliated Hospital of Nanjing Medical University, Nanjing, Jiangsu 210029; \\ ${ }^{2}$ Department of Radiology, Union Hospital Affiliated to Tongji Medical College of Huazhong University of Science and Technology, \\ Wuhan, Hubei 430074, P.R. China
}

Received March 3, 2015; Accepted May 23, 2016

DOI: 10.3892/etm.2016.3535

\begin{abstract}
Transplantation using bone marrow mesenchymal stem cells (BMSCs) is emerging as a potential regenerative therapy after ischemic attacks in the brain. However, it has been questioned because very few transplanted BMSCs are detected homing to and survived in the ischemic region. Improving the cell viability and migration ability under the complex ischemic condition seems very important. The aim of our study is to identify whether hypoxic condition and granulocyte colony-stimulating factor (G-CSF) could improve the cell survival and migration ability of transplanted cells or hypoxic condition could promote BMSC's neural differentiation. BMSCs were treated under either normoxic $\left(21 \% \mathrm{O}_{2}\right)$ or hypoxic $\left(1 \% \mathrm{O}_{2}\right)$ (HP-BMSCs) conditions, no significant apoptosis was observed in hypoxic precondition (HP) group, our study confirmed that HP improves BMSCs proliferation and migration. Meanwhile, neural induction of BMSCs under hypoxic condition exhibited significant superior results than normoxic condition. Additionally, the addition of G-CSF in HP-BMSCs culture media promoted HP efficiency on BMSCs. These findings shed light on novel efficient strategy on the prosperity of BMSCs. Hypoxic preconditioning and
\end{abstract}

Correspondence to: Professor Sheng Liu, Department of Radiology, First Affiliated Hospital of Nanjing Medical University, 300 Guangzhou Road, Nanjing, Jiangsu 210029, P.R. China

E-mail: liusheng@njmu.edu.cn

*Contributed equally

Abbreviation: BMSCs, bone marrow mesenchymal stem cells; HP, hypoxic preconditioning; G-CSF, granulocyte-colony stimulating factor

Key words: bone marrow mesenchymal stem cells, cell proliferation, neural differentiation, granulocyte-colony stimulating factor, migration cultured with G-CSF may become a promising therapeutics for cell-based therapy in the treatments of ischemia stroke.

\section{Introduction}

Ischemic stroke is a major cause of mortality and disability worldwide. Transplantation methods using stem cells, such as bone marrow mesenchymal stem cells (BMSCs), are being developed as potential regenerative therapies for ischemic attacks in the brain. BMSCs are multipotent cells that are able to differentiate into not only mesodermal lineage cells (such as osteoblasts, chondrocytes, adipocytes and muscle cells), but also into neurons and astrocytes $(1,2)$. In addition, basic and clinical studies have suggested that human BMSCs are not antigen-presenting cells and so will not activate the immune system of the host $(3,4)$. However, this has been questioned in recent years because very few transplanted BMSCs are found to home to and survive in the ischemic region of the brain. Several factors may affect cell survival in the acute phase of cerebral infarction, including limited blood supply, hypoxia, trophic factor deficiency, oxidative stress and inflammatory response (5). Improvements in the survival, migration, homing and engraftment rate of transplanted BMSCs are urgently required.

Hypoxic preconditioning (HP) has been shown to be neuroprotective against ischemic brain injury (6). It is reported that HP promotes the survival of embryonic stem cells and provides functional benefits following transplantation into the ischemic rat brain (7). However, little is known of the effect of hypoxic conditioning on BMSC neural differentiation. In the present study, the effects of HP on the proliferation and migration of canine BMSCs as well as the effects on neural differentiation were investigated.

The therapeutic effects of granulocyte-colony stimulating factor (G-CSF) are pleiotropic. G-CSF has been used for bone marrow reconstruction and stem cell mobilization (8). A study has shown that G-CSF may contribute to improving the outcome of BMSC transplantation therapy for central nervous system disorders (9). However, the effect of G-CSF on hypoxically preconditioned BMSCs is not well characterized. 
In the present study, it was hypothesized that HP treatment could improve the proliferation of BMSCs, protect them from necrotic and apoptotic insults and promote their survival in vitro, and that culturing with G-CSF may further promote this efficiency.

\section{Materials and methods}

Cell culture and characterization. In a previous study (10), we successfully cultured BMSCs obtained from 16 healthy adult beagle dogs of either gender and $13.96 \pm 1.0 \mathrm{~kg}$ body weight (Laboratory Animal Centre, Anhui, China). In brief, BMSCs were isolated from bone marrow obtained from the humerus of beagle dogs by density-gradient separation, using lymphocyte separation medium (TBD Science, Tianjin, China). In the present study, BMSCs were isolated by the previously described method (10). Confluent cells at passage 3 (P3) were used for all experiments. These cells were propagated as a monolayer culture in Dulbecco's modified Eagle's medium (DMEM) containing 10\% fetal bovine serum (FBS), $4.5 \mathrm{~g} / \mathrm{l}$ D-glucose, $100 \mathrm{U} / \mathrm{ml}$ penicillin and $100 \mu \mathrm{g} / \mathrm{ml}$ streptomycin. The DMEM, penicillin and streptomycin were from Gibco (Thermo Fisher Scientific, Inc., Waltham, MA, USA). For cell characterization, CD90, CD44 and CD34 expression were identified by flow cytometry (BD FACSCalibur, BD Biosciences, CA, USA). In brief, passage 2 BMSCs were collected in FACS tubes (BD Biosciences) at $2 \times 10^{5}$ cells/tube and washed with FACS buffer. The cells were incubated with antibodies at room temperature for $1 \mathrm{~h}$. Antibodies used were as follows: CD90-PE (561970; BD Pharmingen, San Jose, CA, USA), CD45-PE (555480; BD Pharmingen) and CD34-fluorescein isothiocyanate (FITC; 8011-0349; eBioscience Inc., San Diego, CA, USA). The cells were then washed twice and resuspended in $500 \mu \mathrm{l}$ FACS buffer. The cells incubated with CD90, CD44 or CD34 were incubated with anti-human IgG secondary antibodies labeled with PE or FITC for $1 \mathrm{~h}$. Cells were washed twice and resuspended in $500 \mu 1$ FACS buffer. Cell fluorescence was then evaluated and data were analyzed using FlowJo software (Tree Star, Ashland, OR, USA).

Hypoxic and normoxic conditions. Culture using $1 \% \mathrm{O}_{2}$ was defined as hypoxic and $21 \% \mathrm{O}_{2}$ as normoxic conditions. Hypoxic treatment of cells comprised culturing them in a hypoxic incubator, where the $\mathrm{O}_{2}$ concentration in the chamber was maintained at $1 \%$. Cells of the normoxic control were subjected to the same procedures, with the exception that they were maintained in an atmosphere comprising $21 \% \mathrm{O}_{2}$. To evaluate the effects of hypoxia, BMSCs were divided into the following four groups: Groups HP-1, HP-2 and HP-3, in which cells were cultured under hypoxic conditions for 6,12 and $24 \mathrm{~h}$, respectively, before being transferred to normoxic conditions, and the normoxic group (group N), in which cells were exposed to $21 \% \mathrm{O}_{2}$ throughout the culture.

G-CSF treatment. In order to evaluate the effect of G-CSF on hypoxia-treated BMSCs, the BMSCs were co-cultured with $2 \mathrm{u} /$ cell G-CSF immediately after the hypoxic treatment.

Cell apoptosis. For assessment of cell apoptosis, flow cytometry (BD FACSCalibur) was used to determine the percentages of dead cells and cells undergoing apoptosis as described previously (10). In brief, Annexin $\mathrm{V}^{+}$/propidium iodide ( $\left.\mathrm{PI}^{-}\right)$ cells were considered as early apoptotic while Annexin $\mathrm{V}^{+} / \mathrm{PI}^{+}$ cells were counted as late apoptotic or dead.

Cell viability assay. To detect the viability of the BMSCs, cells were cultured in 96-well plates with 1,000 cells per well. After different treatments, the cell viability was assayed at three different time points: 24, 48 and 72 h. A Cell Counting Kit 8 (CCK8) assay (Dojindo Molecular Technologies, Inc., Kumamoto, Japan) was used according to the manufacturer's protocol. The absorbance (A) at $450 \mathrm{~nm}$ was measured using a microplate reader. All experimental conditions were repeatedly tested as least three times.

Cell migration. The migration ability of BMSCs was detected using a 24-well Transwell cell culture chamber (polycarbonate membrane; Corning Incorporated, Corning, NY, USA). Briefly, an aliquot of $1 \times 10^{4}$ cells was placed into the upper chamber with $100 \mu \mathrm{l}$ serum-free medium. The lower chamber was filled with $600 \mu \mathrm{l}$ medium containing $10 \%$ FBS. After $36 \mathrm{~h}$ incubation, the cells on the upper surface of the filters were removed. The filters were fixed in $4 \%$ paraformaldehyde and the cells that had migrated to the lower side of the filter were stained with crystal violet. Next, the cells were counted under a CKX31 microscope (Olympus Corporation, Tokyo, Japan). At least three chambers from three different experiments were analyzed for each condition.

Cell neuronal differentiation. Neuronal differentiation was induced following previously reported procedures $(11,12)$. Briefly, sub-confluenced BMSCs were preinduced for $24 \mathrm{~h}$ with DMEM, 20\% FBS and $1 \mathrm{mM} \beta$-mercaptoethanol, and then were induced for $6 \mathrm{~h}$ with DMEM, $100 \mathrm{mM}$ butylated hydroxyanisole (BHA) and 2\% dimethylsulfoxide (DMSO). Finally, cells were cultured in maintenance media containing DMEM, $100 \mathrm{mM}$ BHA, 2\% DMSO, $25 \mathrm{mM} \mathrm{KCl}$, $2 \mathrm{mM}$ valproic acid, $10 \mu \mathrm{M}$ forskolin and $\mathrm{N}-2$ supplement for 1-3 days. At the beginning of preinduction, cells were randomly transferred to normoxic and hypoxic conditions, respectively. BMSCs cultured under normoxic conditions with DMEM and 20\% FBS were used as control. The percentages of neuron-like cells were measured by two experienced unrelated individuals blindly via the random selection of 10 non-overlapping visual fields per well. Additionally, the mRNA expression of the neuronal markers nestin (NSE), oligodendrocyte transcription factor 1 (Olig1), glial fibrillary acidic protein (GFAP), microtubule-associated protein 2 (MAP-2) and neurofilament light chain (NF-L), and C-X-C chemokine receptor type 4 (CXCR-4) were analyzed by reverse transcription-quantitative polymerase chain reaction (RT-qPCR).

$R T-q P C R$ analysis. Expression of neuronal markers (Nestin, Olig1, GFAP, MAP-2 and NF-L) and CXCR-4 was analyzed by RT-qPCR. Total RNA was extracted from cultured cells using TRIzol reagent (Thermo Fisher Scientific, Inc.) according to the manufacturer's protocol. RNAs were reverse transcribed using a PrimeScript RT Reagent kit and Oligo dT primer (Takara Bio, Inc., Otsu, Japan). qPCR was performed 
Table I. Primers for canine-specific markers.

\begin{tabular}{|c|c|c|c|}
\hline Gene & Description & Primer sequence & Marker \\
\hline GUSB & Glucuronidase $\beta$ & $\begin{array}{l}\text { F: ACATCGACGACATCACCGTCA } \\
\text { R: GGAAGTGTTCACTGCCCTGGA }\end{array}$ & Reference \\
\hline NSE & Nestin & $\begin{array}{l}\text { F: GGACGGGCTTGGTGTCAATAG } \\
\text { R: AGACTGCTGCAGCCCATTCA }\end{array}$ & Neural progenitor cell \\
\hline GFAP & Glial fibrillary acidic protein & $\begin{array}{l}\text { F: CTAGCTTGGATACAGAGAGG } \\
\text { R: CCAAGTGTATCTGGTTGCCC }\end{array}$ & Astrocyte \\
\hline Olig1 & Oligodendrocyte transcription factor 1 & $\begin{array}{l}\text { F: GTCAATGGCTACATGACTGC } \\
\text { R: GTCATCAATCCACATCGTCC }\end{array}$ & Oligodendrocyte \\
\hline MAP-2 & Microtubule-associated protein 2 & $\begin{array}{l}\text { F: AAGCATCAACCTGCTCGAATCC } \\
\text { R: GCTTAGCGAGTGCAGCAGTGAC }\end{array}$ & Neuron \\
\hline NF-L & Neurofilament light chain & $\begin{array}{l}\text { F: TGAATATCATGGGCAGAAGTGGAA } \\
\text { R: GGTCAGGATTGCAGGCAACA }\end{array}$ & Neuron \\
\hline CXCR-4 & $\mathrm{C}-\mathrm{X}-\mathrm{C}$ chemokine receptor type 4 & $\begin{array}{l}\text { F: GACTCCATGAAGGAACCCTG } \\
\text { R: GCCAGTCAAGAAGATGATGG }\end{array}$ & Cell migration \\
\hline
\end{tabular}

F, forward; R, reverse.

at $95^{\circ} \mathrm{C}$ for $5 \mathrm{sec}$ and $60^{\circ} \mathrm{C}$ for $34 \mathrm{sec}$ in $20 \mu \mathrm{l}$ buffer containing SYBR premix ExTaq II and ROX Reference Dye (Takara Bio, Inc.) and $0.2 \mu \mathrm{M}$ of each primer using SYBR premix DimerEraser (Takara Bio, Inc.) on a 7900HT Fast Real-Time PCR system. GUSB was used as an internal control for $\Delta \Delta \mathrm{Cq}$ analysis (13). The primers are listed in Table I.

Statistical analysis. Data are presented as mean \pm standard deviation. Student's unpaired t-test and one-way analysis of variance were used to compare two or three independent groups, respectively. $\mathrm{P}<0.05$ was considered to indicate a statistically significant difference. All analyses were conducted using SPSS statistical analysis software (version 13.0; SPSS, Inc., Chicago, IL, USA).

\section{Results}

HP facilitated the proliferation and migration of BMSCs. BMSCs were harvested from healthy beagles as previously described (10). When observed under a microscope, typical BMSCs were elongated and spindle-shaped cells with branching extensions under either normoxic $\left(21 \% \mathrm{O}_{2}\right)$ or hypoxic $\left(1 \% \mathrm{O}_{2}\right)$ conditions (Fig. 1A). BMSCs at P3 were characterized by flow cytometry for the phenotypic expression of cell surface markers for mesenchymal stem cells. BMSCs were positive for the cell surface marker CD44 and negative for CD34 and CD90 (Fig. 1B).

To investigate the influence of hypoxia on BMSCs, cells were cultured under hypoxic conditions $\left(1 \% \mathrm{O}_{2}\right)$ prior to being transferred to normoxic conditions $\left(21 \% \mathrm{O}_{2}\right)$. Flow cytometry was used for the assessment of cell apoptosis. No significant apoptosis was observed in the three HP groups or the normoxic group (Fig. 1C).

To detect cell proliferation, cells were moved to normoxic conditions for $24 \mathrm{~h}$ following hypoxia treatment. Subsequent to this, cell proliferation in each group was detected using the CCK8 assay. HP promoted BMSC proliferation in comparison with that in the normoxia group (Fig. 1D). Also, the 12-h hypoxic treatment group exhibited the greatest increase in cell proliferation.

Cell migration to the region of injury is a critical step in stroke therapy. To understand whether HP could affect the migration activity of BMSCs, Transwell assays were performed. The results confirmed that HP treatment facilitated the migration ability of BMSCs, significantly increasing the migration rate of the cells $(\mathrm{P}<0.05$; Fig. $1 \mathrm{E})$.

HP facilitated the neural differentiation of BMSCs. Neuronal differentiation under hypoxic conditions resulted in a significantly higher percentage of neuron-like cells in contrast to normoxic conditions $(68.5 \pm 5.3$ vs. $54.3 \pm 7.4 \%$, $\mathrm{P}<0.05$; Fig. 2A). Furthermore, MAP-2 and NF-L, which are mature neuronal markers, as well as CXCR-4, which contributes to cell migration capacity, were expressed at markedly higher levels in the neuronal induction groups $(\mathrm{P}<0.05)$. Additionally, in the neuronal induction group, these markers were expressed at significantly higher levels under hypoxia than normoxia. However, the expression of Nestin and Olig1 revealed no significant difference between the hypoxic neuronal induction group and the normoxic group (Fig. 2B). The expression of GFAP was higher in the hypoxic neuronal induction group compared with the normoxic group.

$G$-CSF treatment promoted the efficiency of HP on BMSCs. To further evaluate the effect of G-CSF on HP-treated BMSCs, cells were co-cultured with $2 \mathrm{u} /$ cell G-CSF after HP treatment; $2 \mathrm{u}$ /cell G-CSF shows a protective effect on BMSCs (data not shown). The proliferating ability of BMSCs was increased in the G-CSF culture group compared with that of the group treated with hypoxia alone $(\mathrm{P}<0.05$; Fig. $3 \mathrm{~A})$. 
A

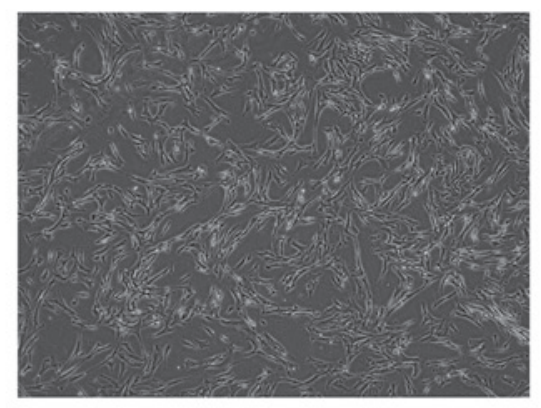

B
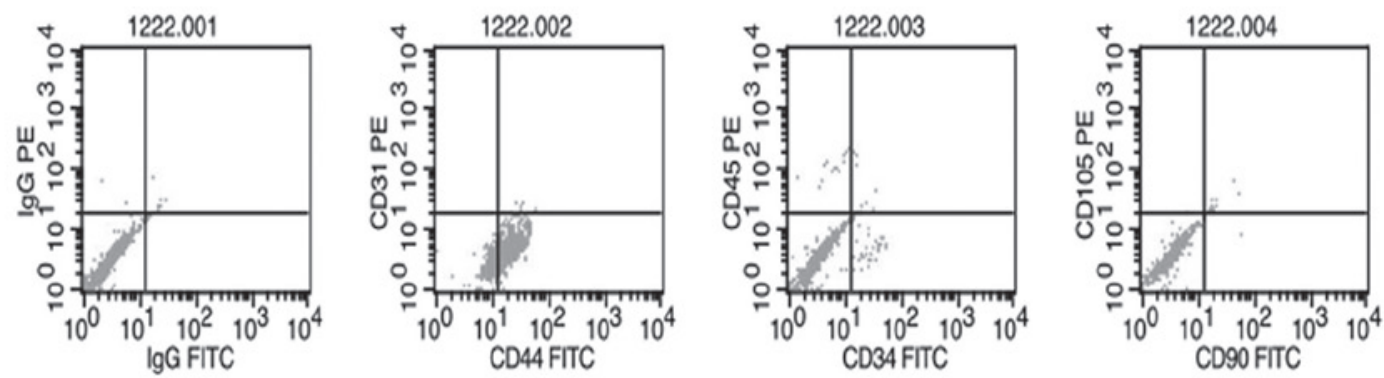

C

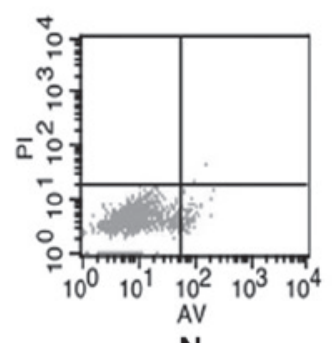

N

D

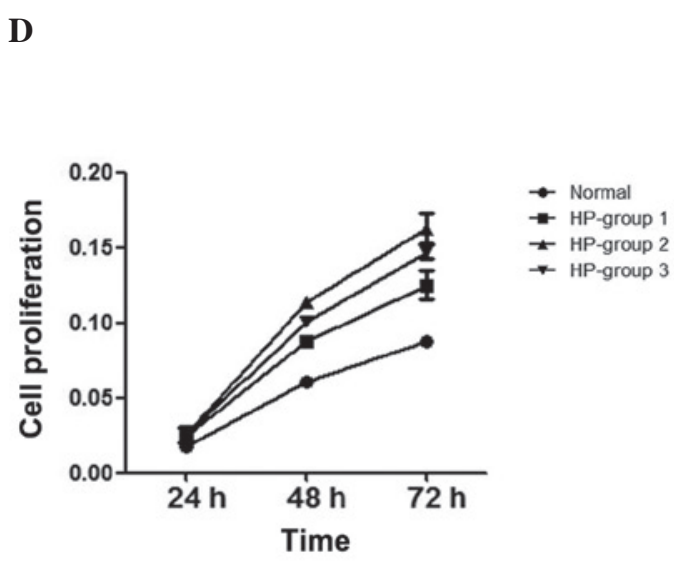

\section{Cell apoptosis}

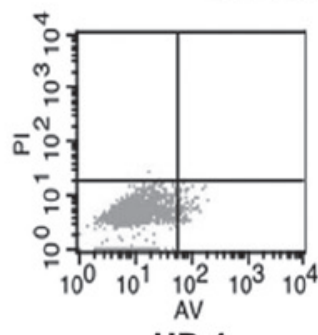

HP-1

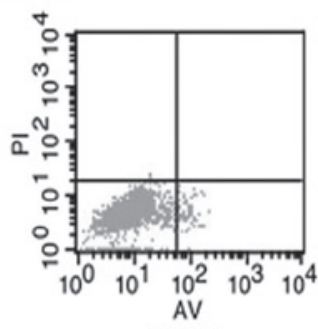

HP-2

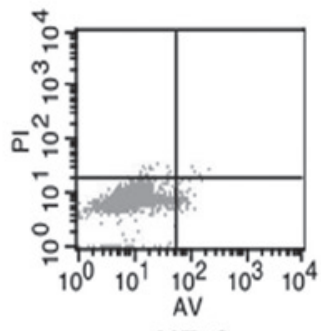

HP-3
E

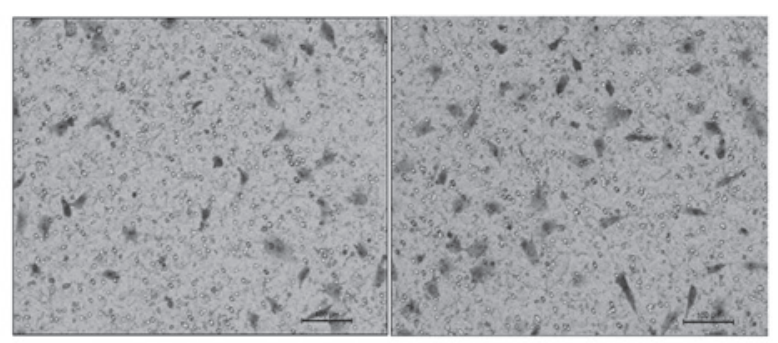

$\mathbf{N}$

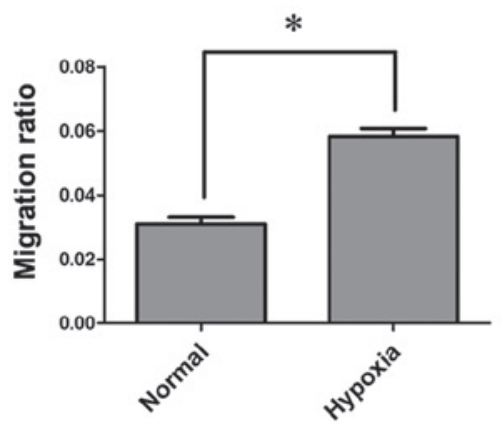

Figure 1. Hypoxic preconditioning (HP) facilitated BMSC proliferation and migration. (A) Phase contrast photo shows typical isolated cells in culture dishes exhibiting spindle or triangular shapes, consistent with the morphology of BMSCs. (B) Characterization of BMSCs isolated from canines. BMSCs were identified by fluorescence-activated cell sorting and the positive expression of CD44 and negative expression of CD34 and CD90 was confirmed. (C) Noticeable apoptosis was not detected in any of the three HP groups or the normoxia (N) group. Lower left quadrant, viable cells (Annexin V-FITC/PI); lower right quadrant, early apoptotic cells (Annexin V-FITC $/ \mathrm{PI}$ ); upper right quadrant, late apoptotic or necrotic cells (Annexin V-FITC $/ \mathrm{PI}^{+}$). (D) $\mathrm{HP}^{-}$promoted BMSC proliferation. (E) HP treatment facilitated the migration ability of BMSCs. The graph presents the summarized data from the Transwell assay. "P<0.05. BMSC, bone marrow mesenchymal stem cell; CD, cluster of differentiation; PE, phycoerythrin; FITC, fluorescein isothiocyanate; PI, propidium iodide; AV, Annexin V. 
A

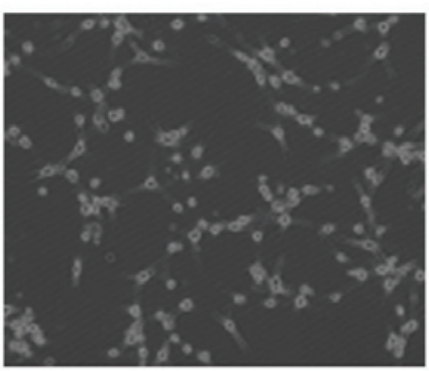

$\mathbf{N}$

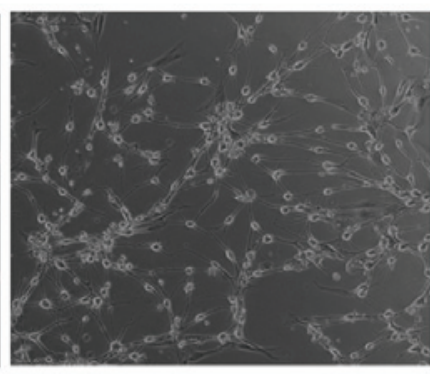

HP

B
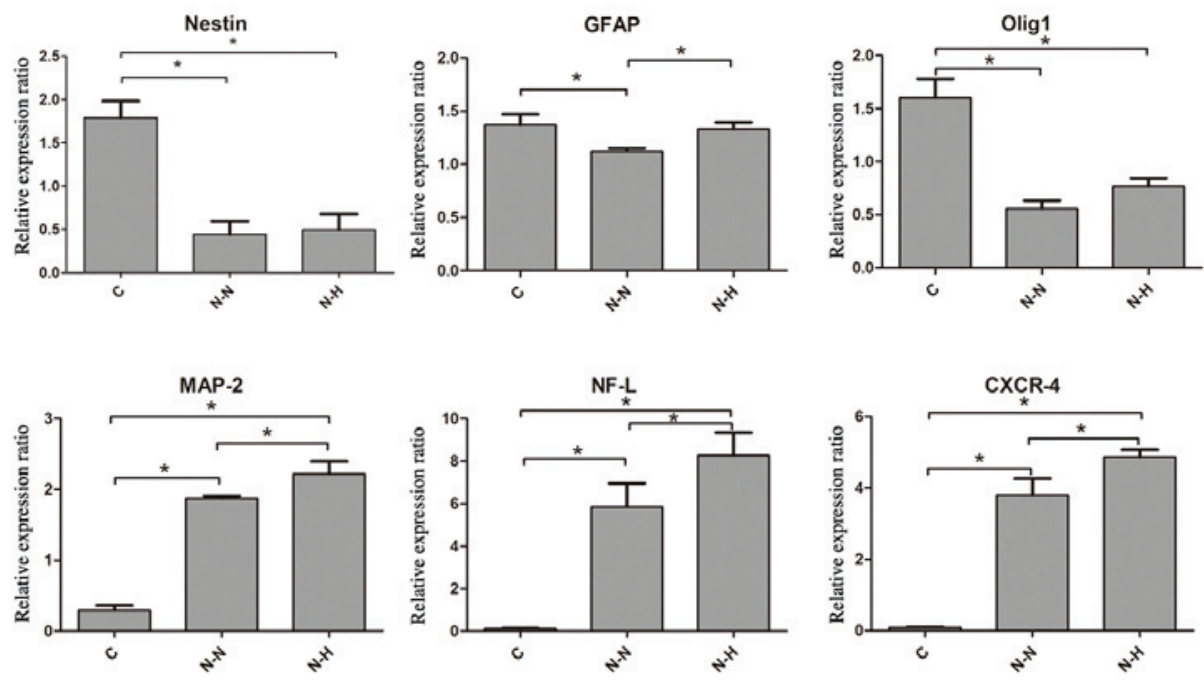

Figure 2. Hypoxic preconditioning (HP) promoted neural differentiation compared with that under normoxic (N) conditions. (A) Neuronal differentiation under hypoxic conditions showed a higher percentage of neuron-like cells in contrast with that under normoxia. (B) Reverse transcription-quantitative polymerase chain reaction assay showed significantly increased MAP-2, NF-L and CXCR-4 mRNA levels in the neuronal induction groups compared with the C group $(\mathrm{P}<0.05)$. Additionally, these markers were expressed at significantly higher levels under hypoxic conditions $(\mathrm{P}<0.05)$. Except for GFAP, the expression of Nestin and Olig1 showed no significant difference between the hypoxic and normoxic neuronal induction groups. "P<0.05. N-N, neuronal induction, normoxic; $\mathrm{N}-\mathrm{H}$, neuronal induction, hypoxic; GFAP, glial fibrillary acidic protein; Olig1, oligodendrocyte transcription factor 1; MAP-2, microtubule-associated protein 2; NF-L, neurofilament light chain; CXCR4, C-X-C chemokine receptor type 4; C, control.

A

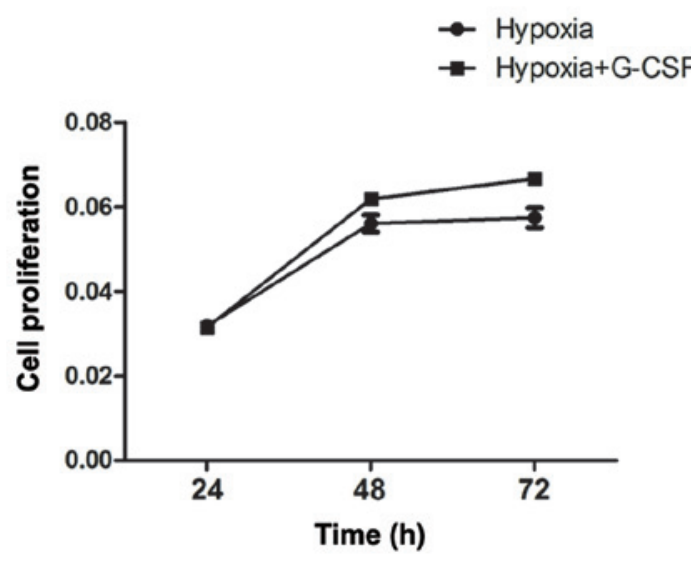

B

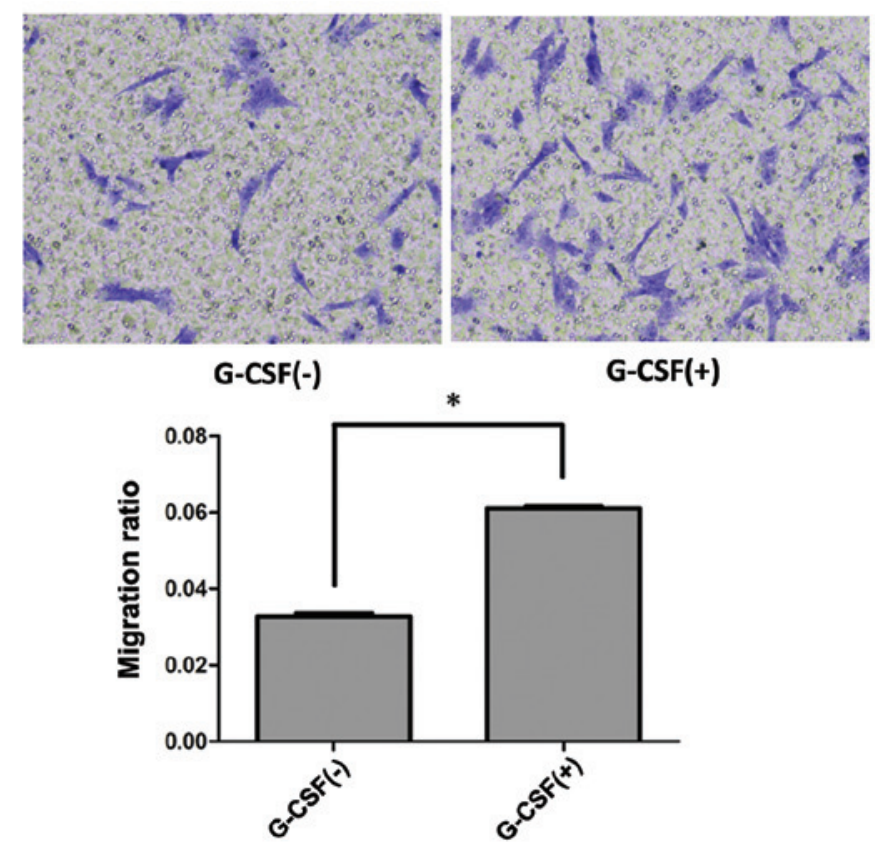

Figure 3. Combined hypoxic preconditioning (HP) and G-CSF treatment facilitated BMSC proliferation and migration. (A) G-CSF treatment promoted BMSC proliferation. (B) Images of the migrating BMSCs under a microscope (stained with crystal violet; magnification, x100). The graph presents the summarized data from the Transwell assay. "P<0.05. G-CSF, granulocyte-colony stimulating factor; BMSC, bone marrow mesenchymal stem cell. 
To further evaluate the cell migration ability, Transwell assays were used. BMSCs were plated in the upper chamber with G-CSF. A greater number of cells migrated following G-CSF culture than with HP treatment only $(\mathrm{P}<0.05$; Fig. 3B).

\section{Discussion}

BMSCs have shown great promise in ischemic tissue repair and have the following advantages: i) No ethical issues, as they are a self-derived bone marrow derivative ii) high proliferation rate, and so can be amplified in a short period of time; iii) no transplant rejection occurs so no immune-suppressants are required. It has been reported that the transplantation of BMSCs promotes the repair and regeneration of nerve tissue within the central and peripheral nervous systems (14). A study of experimental stroke in animals have shown that the transplantation of BMSCs has promising benefits on functional recovery following ischemic stroke or traumatic injury (15). However, the therapeutic effect of BMSC transplantation is limited due to the poor survival and migration of BMSCs. The present in vitro study provided direct evidence that HP preserves BMSCs by increasing their proliferation ability and facilitating their migration rate. In brief, HP is favorable to BMSC culture. This finding is also supported by the 'Adaptive cytoprotection' theory: pretreatment of cells with a moderate stimulus that does not cause cell damage improves the cell tolerance $(16,17)$.

Similar to the results of the present study, in vitro and in vivo studies have shown the benefits of hypoxic pre-conditioned stem cells on neural differentiation $(18,19)$. However, in these studies, neural differentiation and hypoxic conditioning were not conducted simultaneously. In the present study, neural differentiation induced under hypoxic conditions exhibited significantly higher neural differentiation and relative marker expression than that observed under normoxic conditions. This may better mimic the in vivo environment of transplanted mesenchymal stem cells (MSCs), and indicates that transplanted MSCs may act better in ischemic regions than in normal tissues. The stromal cell-derived factor 1/CXCR-4 axis plays an important role in stem cell recruitment (20). The results of the present study showed that CXCR-4 was expressed with neural differentiation concurrently, and hypoxic conditioning could markedly improve this effect. Nichols et al induced $\mathrm{CD}_{133^{+}} \mathrm{ABCG} 2^{+} \mathrm{CXCR} 4^{+} \mathrm{MSC}$ s with human peripheral blood-derived MSCs by priming with $\beta$-mercaptoethanol combined with trans-retinoic acid and culturing in neural basal media (21). These induced MSCs consistently expressed markers of neural lineage and could be recruited predominantly to the site of nervous injury to reduce apoptosis (21). Therefore, we speculate that hypoxia co-induced BMSCs may be more suitable and beneficial in ischemic stroke, although additional in vivo evidence is required.

Cell death following cerebral ischemia is acknowledged to be mediated by a complex pathophysiologic interaction of different mechanisms. Therefore, the present study focused on identifying new and effective strategies that can improve the survival and migration ability of BMSCs. The results demonstrated that G-CSF improved the efficiency of HP in the promotion of canine BMSC survival and migration in vitro. This is consistent with the previously reported finding that
G-CSF treatment following Trypanosoma cruzi infection enhanced the migration and homing of BMSCs (11), and that G-CSF has an influence on recovery following neuronal injury (12). Thus, the present study not only explored a simple and effective strategy to improve the proliferation and migration ability of BMSCs, but also suggested that HP and co-culture with G-CSF may represent a clinically effective and feasible method of manipulation of cell preparations for a better transplantation therapy outcome.

The use of BMSCs from beagle dogs is rarely reported and this type of experimental cell has advantages and superiority as in comparison with small animals without gyri in the brain, the beagle dog brain is structurally and functionally more similar to the human brain. The present study focused on beagle dog BMSCs, which should provide more useful information for clinical transplantation therapy. We plan to detect BMSC viability and migration in vivo in the future. BMSCs are known to secrete numerous biological factors, and under strenuous hypoxia and serum starvation, the expression levels of some of these factors are upregulated. Kinnaird et al reported that these included the following cytokines: Vascular endothelial growth factor, fibroblast growth factor 2, interleukin-6, placental growth factor and monocyte chemoattractant protein-1 (22). The intramyocardial injection of MSC-conditioned media improved collateral blood flow recovery and limb function, and reduced muscle atrophy (22). The changes of these cytokines in our canine model were not tested in the present study. In future studies, we plan to detect these cytokines and signaling that may improve the biological characteristics of BMSCs and their effects on bone marrow cell therapy in ischemic injury.

In conclusion, the present study showed that HP and G-CSF culture can improve the proliferation and migration ability of canine BMSCs in vitro. This study provides a potential novel strategy for BMSCs culture that might be useful in ischemic stroke therapy.

\section{Acknowledgements}

This study was supported by China Postdoctoral Science Foundation (2014M56038 to S. Liu) and National Natural Science Foundation of China (81471764 to S. Liu, 81401497 to X-Q Xu and 81401383 to S-S Lu).

\section{References}

1. Chen Y, Teng FY and Tang BL: Coaxing bone marrow stromal mesenchymal stem cells towards neuronal differentiation: Progress and uncertainties. Cell Mol Life Sci 63: 1649-1657, 2006.

2. Phinney DG and Isakova I: Plasticity and therapeutic potential of mesenchymal stem cells in the nervous system. Curr Pharm Des 11: 1255-1265, 2005.

3. Tse WT, Pendleton JD, Beyer WM, Egalka MC and Guinan EC: Suppression of allogeneic T-cell proliferation by human marrow stromal cells: Implications in transplantation. Transplantation 75: 389-397, 2003.

4. Nemeth, K and Mezey E: Bone marrow stromal cells as immunomodulators. A primer for dermatologists. J Dermatol Sci 77: 11-20, 2015.

5. White BC, Sullivan JM, DeGracia DJ, O'Neil BJ, Neumar RW, Grossman LI, Rafols JA and Krause GS: Brain ischemia and reperfusion: Molecular mechanisms of neuronal injury. J Neurol Sci 179: 1-33, 2000. 
6. Sharp FR, Ran R, Lu A, Tang Y, Strauss KI, Glass T, Ardizzone T and Bernaudin M: Hypoxic preconditioning protects against ischemic brain injury. NeuroRx 1: 26-35, 2004.

7. Theus MH, Wei L, Cui L, Francis K, Hu X, Keogh C and Yu SP: In vitro hypoxic preconditioning of embryonic stem cells as a strategy of promoting cell survival and functional benefits after transplantation into the ischemic rat brain. Exp Neurol 210 656-670, 2008.

8. Weaver CH, Buckner CD, Longin K, Appelbaum FR, Rowley S, Lilleby K, Miser J, Storb R, Hansen JA and Bensinger W: Syngeneic transplantation with peripheral blood mononuclear cells collected after the administration of recombinant human granulocyte colony-stimulating factor. Blood 82: 1981-1984, 1993.

9. Chiba Y, Kuroda S, Osanai T, Shichinohe H, Houkin K and Iwasaki Y: Impact of ageing on biological features of bone marrow stromal cells (BMSC) in cell transplantation therapy for CNS disorders: Functional enhancement by granulocyte-colony stimulating factor (G-CSF). Neuropathology 32: 139-148, 2012.

10. Lu SS, Liu S, Zu QQ, Xu XQ, Yu J, Wang JW, Zhang Y and Shi HB: In vivo MR imaging of intraarterially delivered magnetically labeled mesenchymal stem cells in a canine stroke model PLoS One 8: e54963, 2013.

11. González MN, Dey N, Garg NJ and Postan M: Granulocyte colony-stimulating factor partially repairs the damage provoked by Trypanosoma cruzi in murine myocardium. Int J Cardiol 168: 2567-2574, 2013

12. Schäbitz WR, Kollmar R, Schwaninger M, Juettler E, Bardutzky J, Schölzke MN, Sommer C and Schwab S: Neuroprotective effect of granulocyte colony-stimulating factor after focal cerebral ischemia. Stroke 34: 745-751, 2003.

13. Livak KJ and Schmittgen TD: Analysis of relative gene expression data using real-time quantitative PCR and the 2(-Delta Delta C(T)) Method. Methods 25: 402-408, 2001.

14. Nandoe TR, Hurtado A, Levi AD, Grotenhuis JA and Oudega M: Bone marrow stromal cells for repair of the spinal cord: Towards clinical application. Cell Transplant 15: 563-577, 2006.
15. Li Y and Chopp M: Marrow stromal cell transplantation in stroke and traumatic brain injury. Neurosci Lett 456: 120-123, 2009

16. Kacimi R, Chentoufi J, Honbo N, Long CS and Karliner JS Hypoxia differentially regulates stress proteins in cultured cardiomyocytes: Role of the p38 stress-activated kinase signaling cascade, and relation to cytoprotection. Cardiovasc Res 46: 139-150, 2000

17. Corbucci GG, Marchi A, Lettieri B and Luongo C: Mechanisms of cell protection by adaptation to chronic and acute hypoxia: Molecular biology and clinical practice. Minerva Anestesiol 71: 727-740, 2005.

18. Wei L, Fraser JL, Lu ZY, Hu X and Yu SP: Transplantation of hypoxia preconditioned bone marrow mesenchymal stem cells enhances angiogenesis and neurogenesis after cerebral ischemia in rats. Neurobiol Dis 46: 635-645, 2012.

19. Chung DJ, Wong A, Hayashi K and Yellowley CE: Effect of hypoxia on generation of neurospheres from adipose tissue-derived canine mesenchymal stromal cells. Vet J 199: 123-130, 2014.

20. Wang Y, Fu W, Zhang S, He X, Liu Z, Gao D and Xu T: CXCR-7 receptor promotes SDF- $1 \alpha$-induced migration of bone marrow mesenchymal stem cells in the transient cerebral ischemia/reperfusion rat hippocampus. Brain Res 1575: 78-86, 2014.

21. Nichols JE, Niles JA, DeWitt D, Prough D, Parsley M, Vega S, Cantu A, Lee E and Cortiella J: Neurogenic and neuro-protective potential of a novel subpopulation of peripheral blood-derived CD133+ ABCG2+ CXCR4+ mesenchymal stem cells: Development of autologous cell-based therapeutics for traumatic brain injury. Stem Cell Res Ther 4: 3, 2013.

22. Kinnaird T, Stabile E, Burnett MS, Shou M, Lee CW, Barr S, Fuchs S and Epstein SE: Local delivery of marrow-derived stromal cells augments collateral perfusion through paracrine mechanisms. Circulation 109: 1543-1549, 2004. 